\title{
Correction to: Understanding the Association Between Perceived Financial Well-Being and Life Satisfaction Among Older Adults: Does Social Capital Play a Role?
}

\author{
JeongHee Yeo ${ }^{1} \cdot$ Yoon G. Lee ${ }^{2}$ (D) \\ Published online: 13 July 2019 \\ ๑) Springer Science+Business Media, LLC, part of Springer Nature 2019
}

\section{Correction to: Journal of Family and Economic Issues https://doi.org/10.1007/s10834-019-09634-2}

The article "Understanding the Association Between Perceived Financial Well-Being and Life Satisfaction Among Older Adults: Does Social Capital Play a Role?", written by JeongHee Yeo and Yoon G. Lee, was originally published electronically on the publisher's internet portal (currently SpringerLink) on 19 June 2019 with open access.
With the author(s)' decision to step back from Open Choice, the copyright of the article changed on 4 July 2019 to $\odot$ Springer Science+Business Media, LLC, part of Springer Nature 2019 and the article is forthwith distributed under the terms of copyright.

Publisher's Note Springer Nature remains neutral with regard to jurisdictional claims in published maps and institutional affiliations.

The original article can be found online at https://doi.org/10.1007/ s10834-019-09634-2.

Yoon G. Lee

yoon.lee@usu.edu

JeongHee Yeo

jhyeo@inha.ac.kr

1 Department of Consumer Science, Inha University, Incheon, South Korea

2 Department of Human Development and Family Studies, Utah State University, Logan, UT 84322-2905, USA 